\title{
Assessment of coronary artery remodelling by dual-source CT: a head-to-head comparison with intravascular ultrasound
}

\author{
Sören Gauss, Stephan Achenbach, Tobias Pflederer, Annika Schuhbäck, \\ Werner G Daniel, Mohamed Marwan
}

Department of Cardiology, University of Erlangen, Erlangen, Germany, UK

\section{Correspondence to} Dr Mohamed Marwan, Department of Cardiology, University of Erlangen, Ulmenweg 18, 91054 Erlangen, Germany, UK:

mohamedmarwan@yahoo.com

Accepted 10 March 2011 Published Online First 8 April 2011

\begin{abstract}
Background While it is widely assumed that coronary CT angiography permits detection and quantification of 'positive remodelling' of coronary atherosclerotic lesions, there is a paucity of data comparing CT with established reference methods.
\end{abstract}

Objective To assess the accuracy of dual-source CT for detecting positive versus absent or negative coronary artery remodelling of coronary atherosclerotic lesions as compared with intravascular ultrasound (IVUS).

Methods The datasets were evaluated of 38 patients referred for invasive coronary angiography and in whom an IVUS study of one coronary vessel was performed. Coronary CT angiography was performed within $24 \mathrm{~h}$ before invasive coronary angiography. Using dual-source CT (Siemens Healthcare, Forchheim, Germany), a contrast-enhanced volume dataset was acquired $(120 \mathrm{kV}, 400 \mathrm{~mA} /$ rot, collimation $2 \times 64 \times 0.6 \mathrm{~mm}$, 60-80 ml contrast agent, intravenous). IVUS was performed using a $40 \mathrm{MHz}$ IVUS catheter (Atlantis, Boston Scientific Corporation, Natick, Massachusetts, USA) and motorised pullback at $0.5 \mathrm{~mm} / \mathrm{s}$. 48 corresponding non-calcified and partially calcified plaques within the coronary artery system were identified in both CT and IVUS using bifurcation points as fiducial markers. In CT datasets, multiplanar reconstructions orthogonal to the centre line of the coronary artery were rendered and cross-sectional vessel area was measured at the site of maximal narrowing as well as at a reference segment proximal to the lesion for each of the 48 plaques. The remodelling index (RI) was calculated by dividing the vessel area at the site of maximal narrowing by the area of the reference segment. Corresponding vessel areas and Rls were also determined in IVUS.

Results CT classified 41 plaques as positively remodelled $(\mathrm{Rl} \geq 1.05)$ and seven as having either absent or negative remodelling $(\mathrm{R} \mid<1.05)$. In IVUS 29 plaques demonstrated positive remodelling, while 19 did not. Mean cross-sectional vessel areas measured by CT at the lesion and at the reference segment were $19 \pm 5 \mathrm{~mm}^{2}$ and $17 \pm 5 \mathrm{~mm}^{2}$, respectively, versus $18 \pm 5 \mathrm{~mm}^{2}$ and $17 \pm 5 \mathrm{~mm}^{2}$ for IVUS (mean difference $1 \pm 2 \mathrm{~mm}^{2}$ and $-0.2 \pm 1 \mathrm{~mm}^{2}, \mathrm{p}<0.0001$ and 0.8 , respectively). The mean $\mathrm{Rl}$ in CT was significantly larger than in IVUS $(1.2 \pm 0.2$ vs $1.1 \pm 0.2, p<0.0001)$. Correlation between CT and IVUS was higher for vessel area measurements $(r>0.9, p<0.0001)$ than for remodelling indices $(r=0.7, p<0.0001)$ with Bland-Altman analysis showing a systematic overestimation of vessel areas and $\mathrm{RI}$ in CT. Interobserver agreement was moderate for CT and IVUS measurements. Receiver operating characteristic curve analysis showed that a RI of 1.1 in CT identified positively remodelled plaques in IVUS with a sensitivity of $83 \%$ and a specificity of $78 \%$ (area under the curve $=0.8$, $95 \% \mathrm{Cl} 0.7$ to 1.0). Using the standard cut-off point of 1.05 to identify positively remodelled plaques in CT resulted in a sensitivity of $100 \%$, and a specificity of $45 \%$.

Conclusion Coronary CT angiography allows analysis of coronary artery remodelling. The degree of positive remodelling is typically overestimated by CT. A threshold of 1.1 for the $\mathrm{Rl}$ may be optimal to classify plaques as 'positively remodelled' in coronary CT angiography.

\section{INTRODUCTION}

The response of coronary arteries to atherosclerosis and plaque growth-whether with compensatory enlargement or shrinkage-is referred to as 'coronary artery remodelling'. The assessment of compensatory enlargement or positive remodelling of coronary arteries has attracted a lot of attention owing to the propensity for positively remodelled coronary artery plaques to cause future cardiac events based on histopathological ${ }^{1} 2$ and clinical studies. $^{3-7}$ Intravascular ultrasound (IVUS) has been the preferred method for the assessment of coronary artery remodelling in vivo. ${ }^{3-13}$ Multidetector CT is a non-invasive modality which can visualise the coronary artery lumen as well as coronary atherosclerotic plaque and has been extensively investigated. ${ }^{14-27}$ Furthermore, previous data on coronary vessel area measurements using CT compared with IVUS were promising. 2829

It is widely assumed that coronary CT angiography permits detection and quantification of positive remodelling of coronary atherosclerotic lesions, yet there is a paucity of data to validate CT against established reference methods. ${ }^{28}{ }^{29}$ Moreover, previous studies assessing coronary artery remodelling in CT were performed using oldergeneration scanners with limited temporal and spatial resolution. We assessed the accuracy of dualsource CT (DSCT) for detecting positive versus absent or negative coronary artery remodelling in patients with suspected coronary artery disease compared with IVUS.

\section{PATIENTS AND METHODS}

From a registry of 68 patients, who underwent invasive coronary angiography with IVUS of at least one coronary vessel, and in whom coronary 
CT angiography had been performed within $24 \mathrm{~h}$ before coronary angiography, datasets of 38 patients with either excellent or good image quality were included in the analysis. Thirty patients were excluded owing to suboptimal CT image quality $(n=7)$, extensively calcified coronaries $(n=9)$, absence of relevant plaque burden $(n=9)$ or owing to a poor IVUS image quality $(n=5)$. All patients had been referred for invasive coronary angiography and IVUS of at least one coronary vessel had been performed for clinical reasons. No patients with acute coronary syndromes were included in this study. All patients gave an informed consent and the study protocol was approved by the local ethics committee.

\section{DSCT examination}

All patients were in sinus rhythm at the time of CT data acquisition. Patients with a mean heart rate $>60$ beats $/$ min received $100 \mathrm{mg}$ of atenolol orally $45-60 \mathrm{~min}$ before DSCT. If the mean heart rate remained $>60$ beats/min at the time of scanning, up to four doses of metoprolol $5 \mathrm{mg}$ were given intravenously. All patients received isosorbide dinitrate $0.8 \mathrm{mg}$ sublingually before DSCT.

Coronary CT angiography was performed in all patients using DSCT (Definition, Siemens Medical Solutions, Forchheim, Germany) within $24 \mathrm{~h}$ before invasive coronary angiography. A contrast-enhanced volume dataset was acquired with retrospective ECG gating using tube current modulation. Acquisition parameters for CT angiography were $0.6 \mathrm{~mm}$ collimation, $330 \mathrm{~ms}$ rotation time, $120 \mathrm{kV}$ tube voltage and a tube current of $400 \mathrm{~mA}$. Scan direction was craniocaudal, and the scan volume ranged from the mid-pulmonary artery to below the diaphragmatic face of the heart. After placing an antecubital 18-G intravenous access, the contrast agent transit time (iopromide, $370 \mathrm{mg}$ of iodine/ml; Ultravist 370, Schering, Berlin, Germany) was assessed by injecting a test bolus of $10 \mathrm{ml}$ contrast followed by a saline flush of $50 \mathrm{ml}$, both at a flow rate of $6 \mathrm{ml} / \mathrm{s}$ using a dual-head power injector (CT Stellant, Medrad Inc, Indianola, Pennsylvania, USA). Contrast transit time was defined as the time between the start of contrast injection and maximum enhancement in the ascending aorta at the level of the coronary ostia. For angiographic CT data acquisition, a delay of $2 \mathrm{~s}$ longer than the contrast transit time was used to ensure adequate contrast enhancement of the coronary arteries. The volume of contrast agent injected for the scan depended on the estimated scan duration. Contrast was injected at a flow rate of $6 \mathrm{ml} / \mathrm{s}$ for the same duration as data acquisition, but for at least $10 \mathrm{~s}$. Contrast injection was followed by a $50 \mathrm{ml}$ saline chaser bolus $(6 \mathrm{ml} / \mathrm{s})$.

\section{CT image reconstruction}

Using a half-scan reconstruction algorithm (temporal resolution $83 \mathrm{~ms}$ ), overlapping axial cross-sectional images with $0.75 \mathrm{~mm}$ slice thickness and $0.4 \mathrm{~mm}$ increment were reconstructed using a medium sharp convolution kernel (B26f). Using an internal algorithm, the scanner automatically suggested a best diastolic phase. If artefacts were still to be seen, further diastolic phases in $2 \%$ intervals of the cardiac cycle were reconstructed and then the diastolic phase reconstruction with minimal artefacts was evaluated.

\section{IVUS}

After intracoronary injection of $0.2 \mathrm{mg}$ nitroglycerin, IVUS was performed using a $40 \mathrm{MHz}$ IVUS catheter (Atlantis, Boston Scientific Corporation, Natick, Massachusetts, USA) and motorised pullback at $0.5 \mathrm{~mm} / \mathrm{s}$. Data were stored on DVD for further offline analysis.

\section{CT and IVUS image analysis}

Forty-eight exactly corresponding non-calcified or partially calcified plaques within the coronary artery system were identified by one observer in both DSCT and IVUS datasets using bifurcation points as fiducial markers. For each plaque, the site of maximum narrowing - as visually estimated-as well as a reference point proximal to the lesion were then identified in CT and IVUS and images were stored. For assessment of interobserver variability, 15 consecutive lesions were then analysed by two observers in both modalities, otherwise for the remaining 33 lesions, analysis was performed by one independent observer in each modality. CT datasets were analysed on a dedicated workstation (Multimodality Workplace; Siemens Medical Solutions, Forchheim, Germany). Multiplanar reconstructions orthogonal to the centre line of the coronary artery were rendered and using a visually adjusted image display setting, cross-sectional vessel area was measured at the site of maximal narrowing as estimated visually (figures 1 and 2). Similarly, cross-sectional vessel area was determined at a reference segment without detectable plaque proximal to the lesion for each of the 48 plaques. In the absence of a segment free of plaque, the least diseased segment between the lesion and the coronary ostium or major bifurcation was used. IVUS datasets were viewed using a commercially available software package (iReview, Boston Scientific Corp, version 1.0.2544.18303). Crosssectional vessel area was measured by tracing the external elastic membrane at the site of maximal luminal narrowing and in the proximal reference segment (figure 3). Similarly, in the absence of a segment free of plaque, the least diseased segment between the lesion and the coronary ostium or major bifurcation was used. The remodelling index (RI) was calculated in CT and IVUS datasets by dividing the vessel area at the site of maximal narrowing by the area of the reference segment. A previously suggested, $^{5} \mathrm{RI} \geq 1.05$ was used to define plaques as positively remodelled.
Figure 1 (A) Multiplanar reconstruction of the left anterior descending coronary artery (LAD) showing a non-calcified plaque in the proximal LAD just before the origin of a diagonal branch. (B) Intravascular ultrasound image of the same patient showing the same non-calcified plaque in the proximal $L A D$.
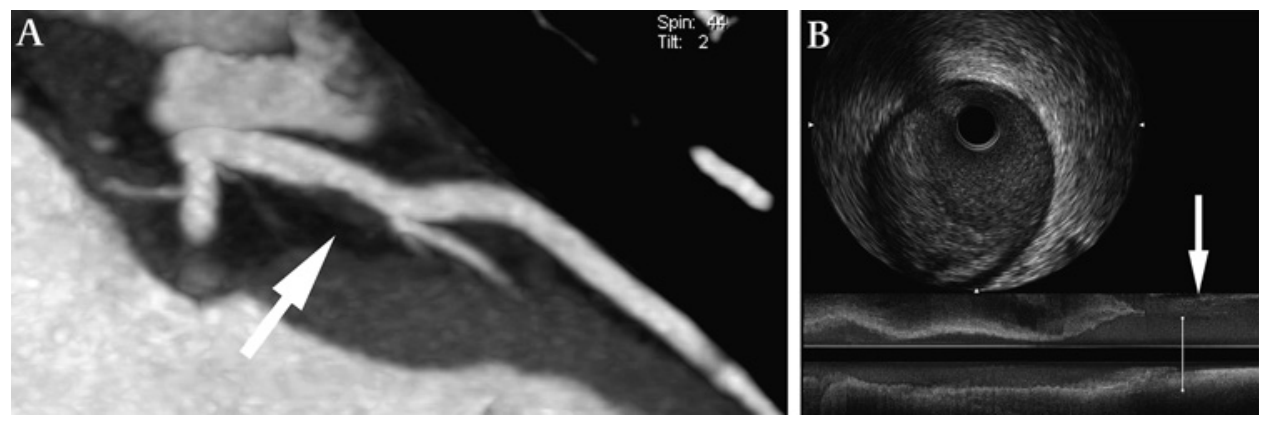
Figure 2 (A, B) Multiplanar reconstruction orthogonal to the centre line of the coronary artery is rendered for the same plaque shown in figure 1 at the site of maximal narrowing $(A)$ and at a reference segment proximal to the lesion (B). (C, D) Manual tracing of the cross-sectional vessel area at the site of maximal narrowing $(\mathrm{C})$ as well as at the reference segment (D).
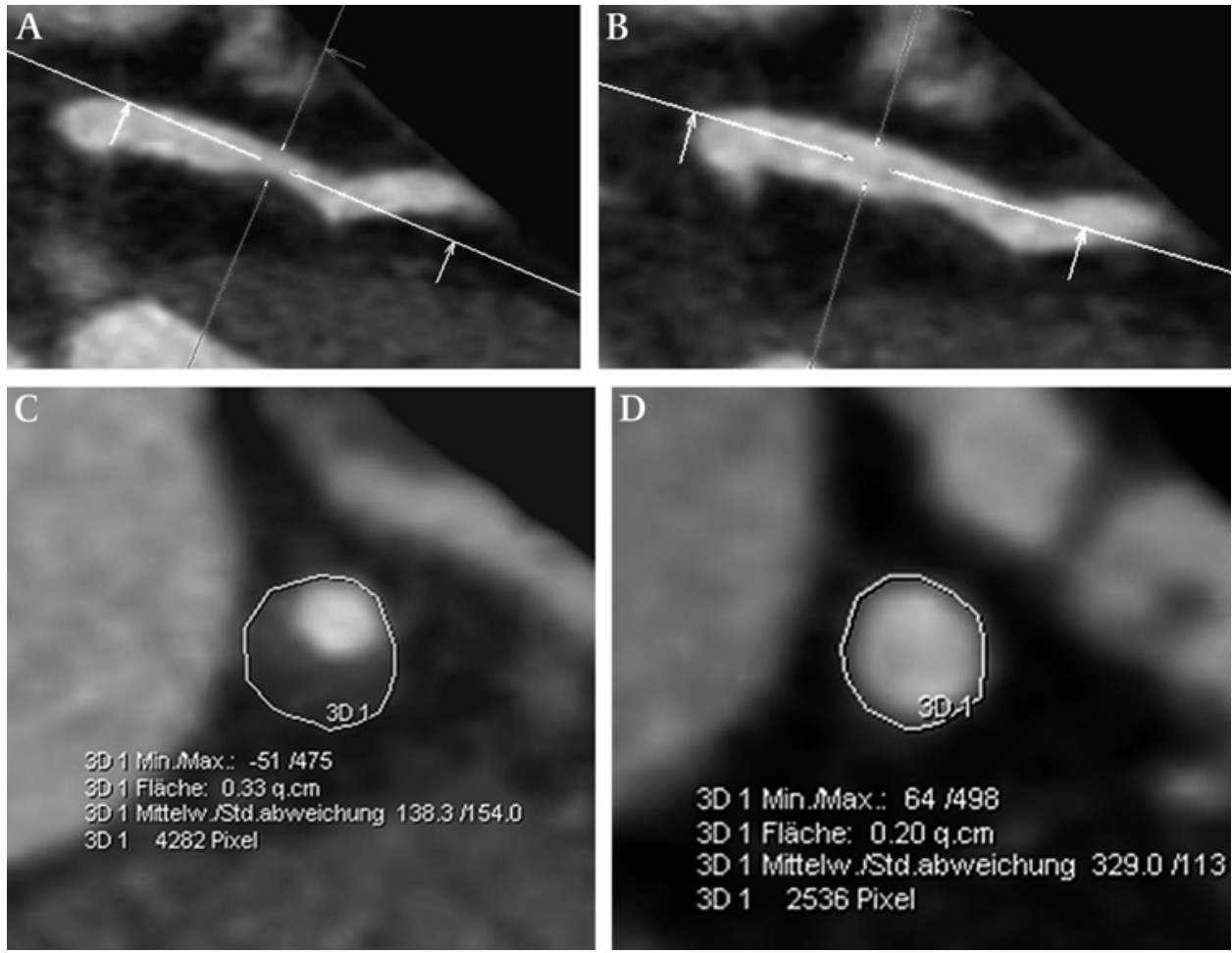

\section{Statistical methods}

Statistical analysis was done using SPSS for Windows release 18.0 (SPSS Inc). All data are expressed as mean \pm SD for continuous variables. Correlations were performed using Spearman's correlation coefficient. Agreement was assessed using Bland-Altman analysis. Wilcoxon signed-rank test was used to compare non-parametric data. Receiver operating characteristic (ROC) curve analysis was performed to obtain the best cut-off point needed to define plaques as positively remodelled using IVUS as the 'gold standard'.

\section{RESULTS}

Datasets of 38 patients (26 men, $59 \pm 10$ years) were evaluated. The mean heart rate during CT examination was $58 \pm 7 \mathrm{bpm}$. Patient characteristics are shown in table 1. Forty-eight exactly corresponding non-calcified $(n=37)$ and partially calcified $(n=11)$ plaques in both IVUS and CTwere assessed. The distribution of the studied plaques was as follows: 32 plaques in the left anterior descending coronary artery, 13 in the right coronary artery, 2 in the left main coronary artery and one in the left circumflex coronary artery. CT classified 41 plaques as positively remodelled $(R I \geq 1.05)$ and seven as having either absent or negative remodelling $(\mathrm{RI}<1.05)$. In IVUS, 29 plaques were positively remodelled versus 19 with absent or negative remodelling. The mean cross-sectional vessel areas measured by $\mathrm{CT}$ at the site of the lesion with maximal narrowing and at the reference segment were $19 \pm 5 \mathrm{~mm}^{2}$ and $17 \pm 5 \mathrm{~mm}^{2}$, respectively versus $18 \pm 5 \mathrm{~mm}^{2}$ and $17 \pm 5 \mathrm{~mm}^{2}$ for IVUS (mean difference $1 \pm 2 \mathrm{~mm}^{2}$ and $-0.2 \pm 1 \mathrm{~mm}^{2}, \mathrm{p}<0.0001$ and 0.8 , respectively). The mean RI in CT was $1.18 \pm 0.17$ (range 0.85-1.69), whereas in IVUS the mean RI was $1.09 \pm 0.17$ (range 0.78-1.62) (mean difference $0.1 \pm 0.1 \mathrm{~mm}^{2}, \mathrm{p}<0.0001$ ). The correlation between CT and IVUS was closer for vessel area measurements $(r>0.9$, $\mathrm{p}<0.0001)$ than for remodelling indices $(\mathrm{r}=0.7, \mathrm{p}<0.0001)$ (figure 4). A Bland-Altman plot showed a better agreement between CT and IVUS for vessel area measurements at the
Figure 3 (A, B). Intravascular ultrasound images corresponding to the plaque shown in figure 2 with manual tracing of the cross-sectional vessel area at the site of maximal narrowing (A) and at the reference segment (B).
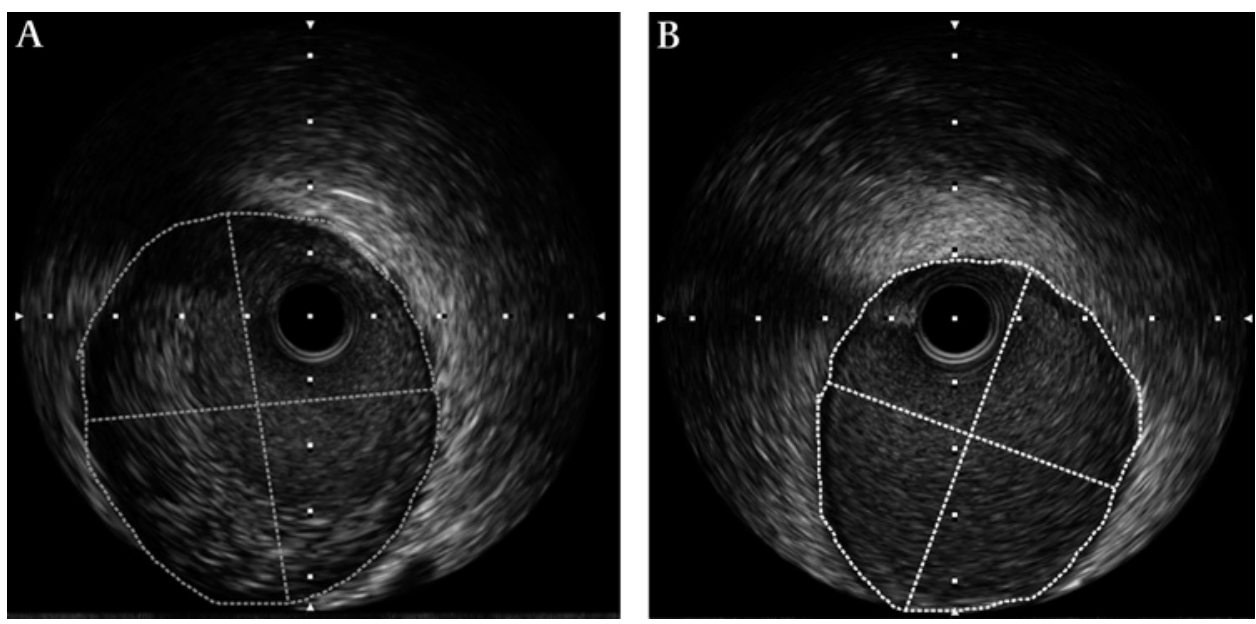
Table 1 Patient characteristics

\begin{tabular}{ll}
\hline Characteristics & Value \\
\hline Age, years, mean \pm SD (range) & $59 \pm 10(34-87)$ \\
Heart rate, bpm, mean \pm SD (range) & $58 \pm 7$ \\
Male gender, $\mathrm{n}(\%)$ & $26(68)$ \\
BMl, mean \pm SD & $26 \pm 7$ \\
History, $\mathrm{n}(\%)$ & \\
Hypertension & $30(79)$ \\
Diabetes & $5(13)$ \\
Dyslipidaemia & $29(76)$ \\
Smoking & $4(11)$ \\
Family history of CAD & $13(34)$ \\
Effective radiation dose, $\mathrm{mSv}$, mean $\pm S D$ & $9 \pm 3$ \\
\hline
\end{tabular}

$\mathrm{BMl}$, body mass index; CAD, coronary artery disease.

reference segment than area measurements at the lesion site (mean difference $-0.2 \mathrm{~mm}^{2}$ vs $1.2 \mathrm{~mm}^{2}, 95 \%$ limits of agreement 2.8 to $-3.1 \mathrm{~mm}^{2}$ vs 4.6 to $-2.3 \mathrm{~mm}^{2}$, respectively) (figure 5 ). There was a systematic overestimation of the vessel area at the lesion site in CT in comparison with IVUS, whereas for

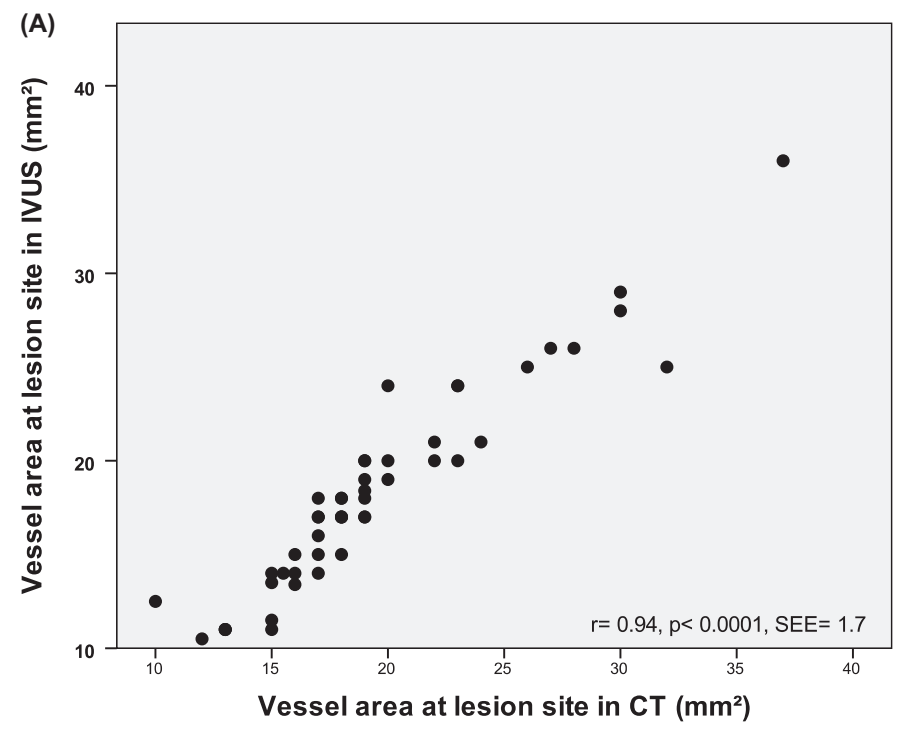

area measurements at the reference segment, a minimal trend towards underestimation was observed. Similarly, a Bland-Altman plot showed a moderate to good agreement between CT and IVUS for remodelling indices, with a systematic trend towards overestimation of the RI in CT versus IVUS (mean difference $0.1,95 \%$ limits of agreement 0.3 to -0.2 ) (figure 6).

In order to assess interobserver agreement, 15 consecutive lesions were analysed by both observers in both modalities. There was no significant difference between both observers for cross-sectional vessel area measurements in CT and IVUS (at lesion or reference site, $\mathrm{p}>0.1$ for all). Bland-Altman plots showed moderate agreement between both observers for CT and IVUS measurements (figure 7). The mean difference for lesion area measurements was $0.3 \mathrm{~mm}^{2}$ in CT vs. $0.4 \mathrm{~mm}^{2}$ in IVUS ( $95 \%$ limits of agreement 3 to $-2.5 \mathrm{~mm}^{2}$ vs 2 to $-2 \mathrm{~mm}^{2}$, respectively). For reference area measurements, the mean difference between both observers was $0.4 \mathrm{~mm}^{2}$ in CT vs $0.2 \mathrm{~mm}^{2}$ in IVUS ( $95 \%$ limits of agreement 3 to -2 vs 2 to -2 , respectively).

ROC curve analysis showed that a RI of 1.1 identified positively remodelled plaques in CT angiography with a sensitivity

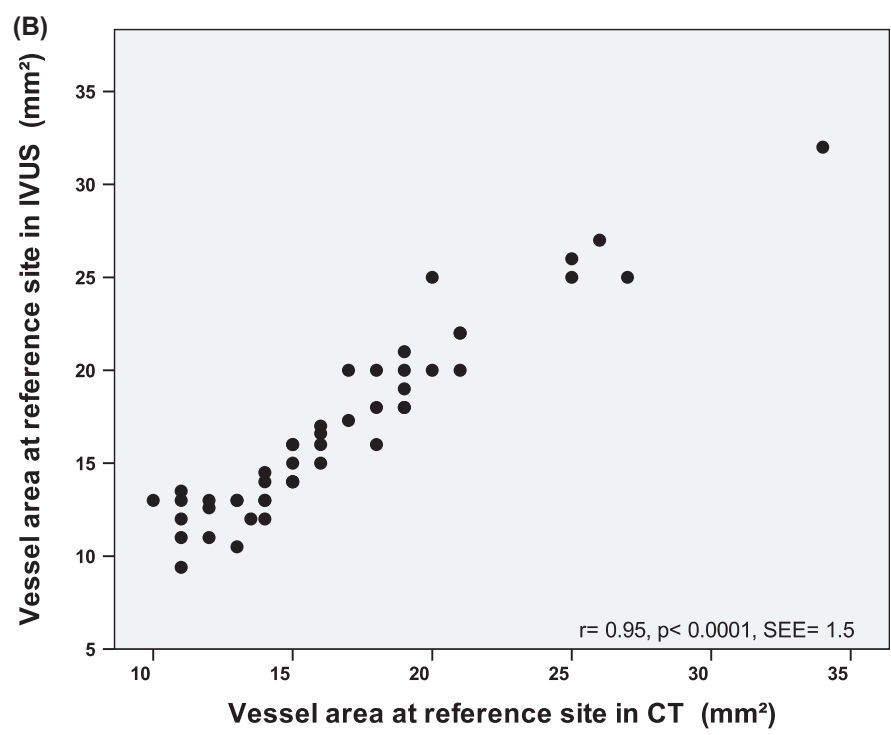

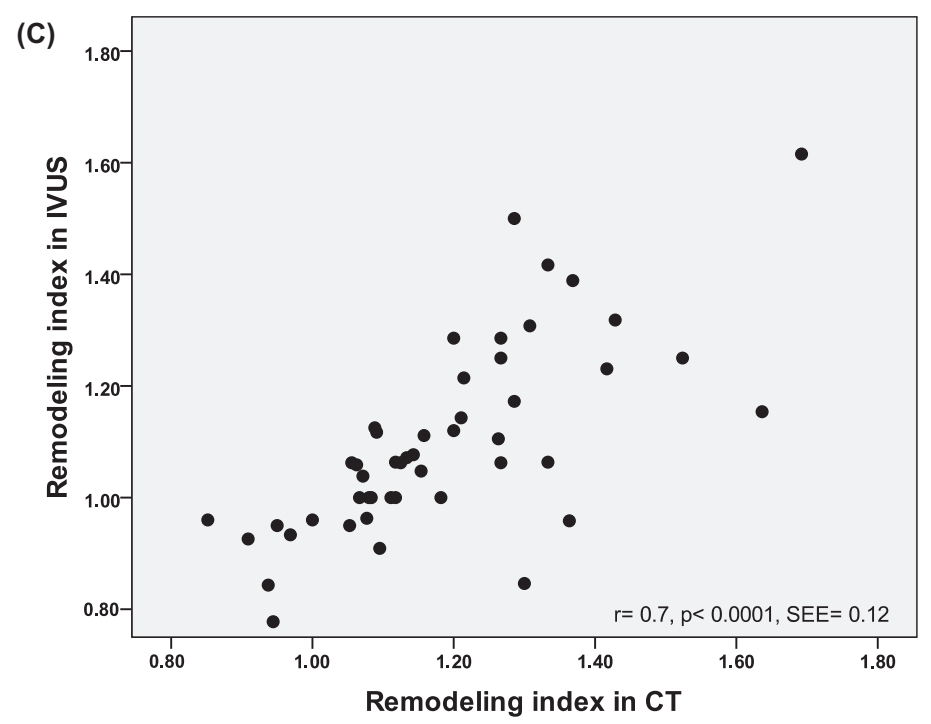

Figure 4 Correlation plots for (A) CT vessel area measurements at the site of the lesion compared with intravascular ultrasound (IVUS); (B) CT vessel area measurements at reference site compared with IVUS; (C) remodelling indices in CT compared with IVUS. SEE, standard error of the estimate. 
A Vessel area measurement at the lesion in CT and
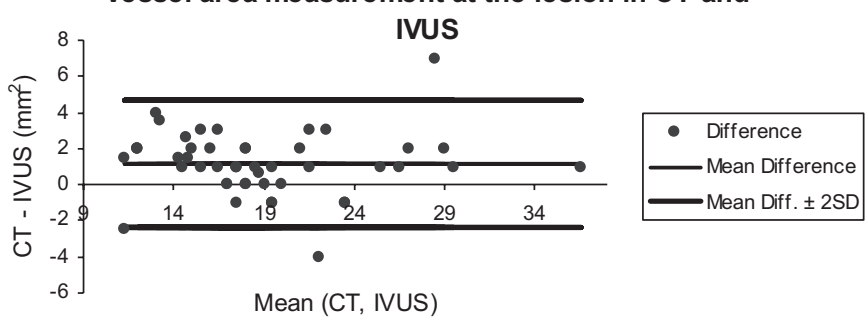

B Vessel area measurement at reference segment in

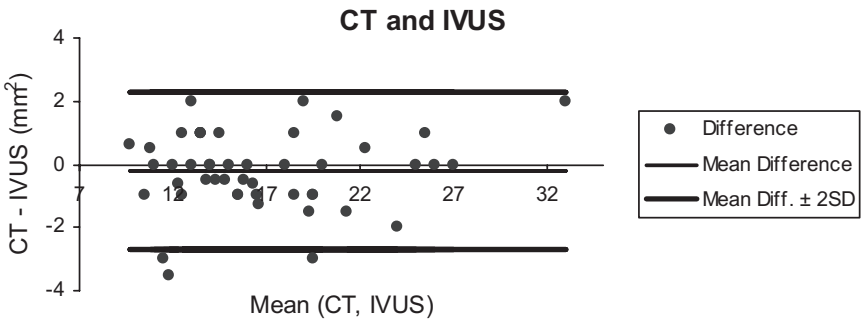

Figure 5 (A, B) Bland-Altman plots for the agreement between CT and intravascular ultrasound (IVUS) for vessel area measurement at the site of the lesion $(A)$ and at the reference segment $(B)$ (mean difference $1.2 \pm 2 \mathrm{~mm}^{2}$ and $-0.2 \pm 1 \mathrm{~mm}^{2}$, respectively, $95 \%$ limits of agreement 4.6 to $-2.3 \mathrm{~mm}^{2}$ and 2.8 to $-3.1 \mathrm{~mm}^{2}$, respectively).

of $83 \%$ and a specificity of $78 \%$ (area under the curve $=0.8,95 \%$ CI 0.7 to 1.0) (figure 8). When the standard cut-off point of 1.05 for the RI was used to identify positively remodelled plaques in CT, this resulted in a sensitivity of $100 \%$, and a specificity of $45 \%$ as compared with IVUS.

\section{A Agreement between both readers for lesion area measurements in $\mathrm{CT}$}

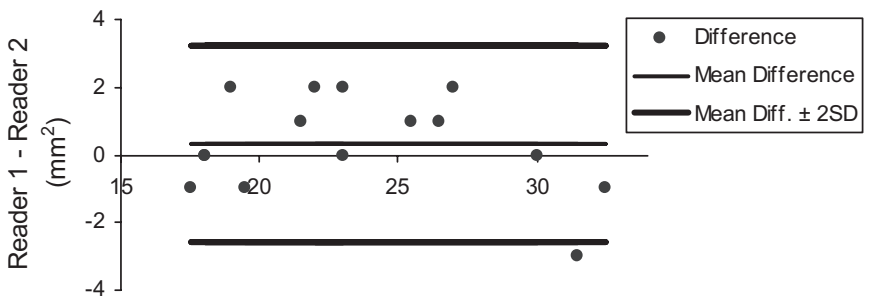

Mean (Reader 1, Reader 2)

C

Agreement between both readers for lesion area measurements in IVUS

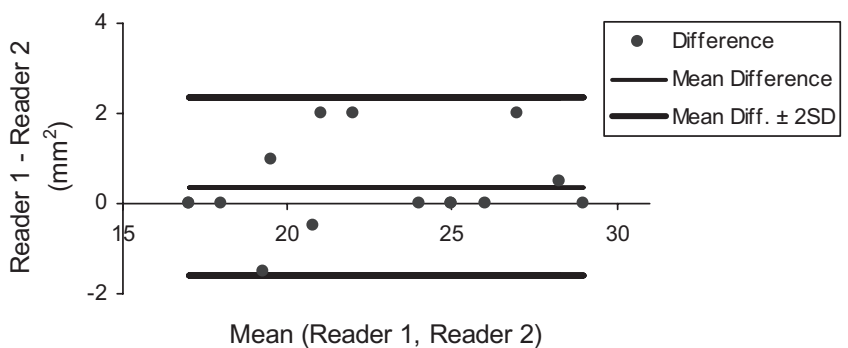

Remodeling indices in CT and IVUS

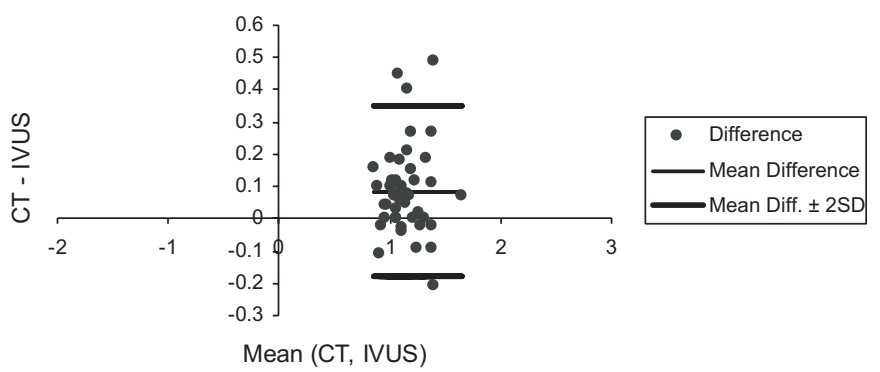

Figure 6 Bland-Altman plot for the agreement between CT and intravascular ultrasound (IVUS) for remodelling indices (mean difference $0.1 \pm 0.1,95 \%$ limits of agreement 0.3 to -0.2 ).

\section{DISCUSSION}

The assessment of coronary artery remodelling using noninvasive imaging modalities is of potential clinical interest owing to the propensity of positively remodelled coronary atherosclerotic plaques to rupture and cause future cardiac events. This information can affect risk stratification and subsequent treatment decisions. Previous CT studies looking at the morphology of culprit lesions in patients presenting with acute coronary syndromes have shown that positive remodelling is characteristic of such lesions. ${ }^{30-33}$ In a prospective study, Motoyama et al recently showed that patients with atherosclerotic plaques which displayed both positive remodelling and low attenuation areas in CT angiography are at high risk of developing acute coronary syndromes. ${ }^{7}$ All the more surprising is the fact that there is a paucity of data concerning

\section{B Agreement between both readers for reference area measurments in $\mathrm{CT}$}

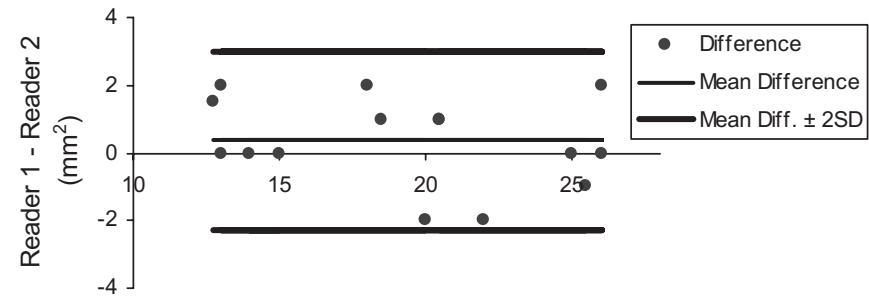

Mean ( Reader1, Reader 2)

\section{Agreement between both readers for reference area measurements in IVUS}

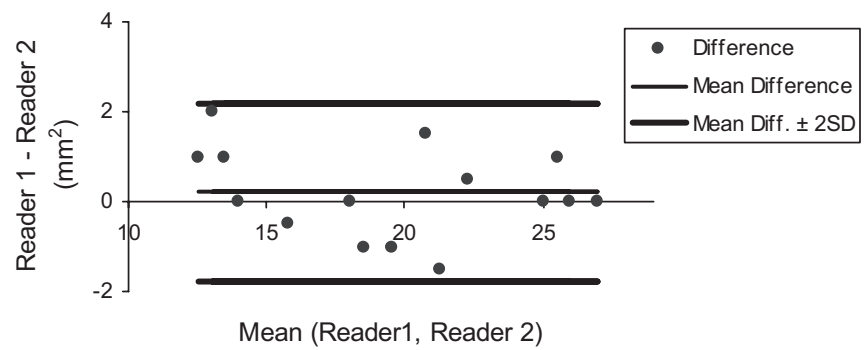

Figure $7(A, B)$ Bland-Altman plots for agreement between both readers for CT lesion area measurements $(A)$ and reference area measurement (B) (mean difference $0.3 \pm 1 \mathrm{~mm}^{2}$ and $0.4 \pm 1 \mathrm{~mm}^{2}$, respectively, $95 \%$ limits of agreement 3 to $-2.5 \mathrm{~mm}^{2}$ and 3 to $-2 \mathrm{~mm}^{2}$, respectively). (C, D) Bland-Altman plots for agreement between both readers for intravascular ultrasound (IVUS) lesion area measurements (C) and reference area measurement (D) (mean difference $0.4 \pm 1 \mathrm{~mm}^{2}$ and $0.2 \pm 1 \mathrm{~mm}^{2}$, respectively, 95\% limits of agreement 2 to $-2 \mathrm{~mm}^{2}$ for both measurements). 


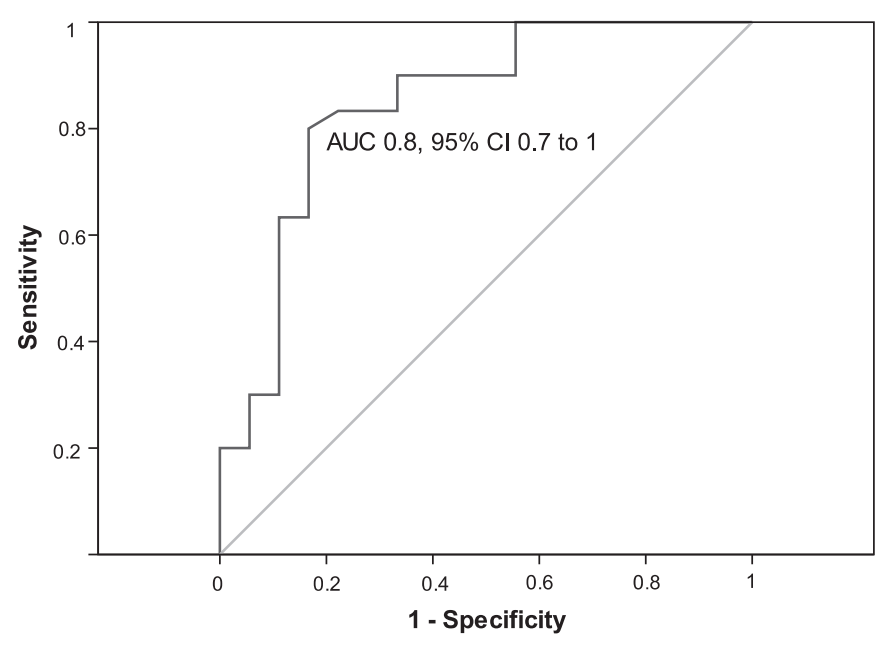

Figure 8 Receiver operating characteristic curve for identification of positively remodelled plaques in CT using different remodeling indices (area under the curve(AUC) $0.8,95 \% \mathrm{Cl} 0.7$ to 1 ).

the accuracy of identifying the extent of coronary remodelling in CT angiography. ${ }^{29}$

We analysed 48 non-calcified and partially calcified coronary atherosclerotic plaques in 38 patients using contrast-enhanced DSCT and IVUS. The reproducibility of vessel area measurements using contrast-enhanced CT angiography compared with IVUS has been recently assessed by our research group. ${ }^{34}$ In CT, 41 plaques were classified as positively remodelled (RI $\geq 1.05)$. Of these 41 plaques, IVUS identified only 29 plaques as positively remodelled $(R I \geq 1.05)$. The mean vessel area at the site of maximal narrowing was significantly higher in CT than with IVUS with a systematic trend towards overestimation in CT. The mean vessel area at the reference segment was not significantly different in both modalities with a higher mean RI in CT versus IVUS ( $1.2 \pm 0.2$ vs $1.1 \pm 0.2$, respectively, $p<0.0001)$. These results are partly in line with an earlier study by Achenbach et $a l^{29}$ where coronary artery remodelling was assessed using 16 slice multidetector CT, and validated by IVUS in a subset of 13 patients. In their study, the mean vessel area was similarly higher in CT than in IVUS $\left(20 \pm 7 \mathrm{~mm}^{2} \mathrm{vs} 18 \pm 8 \mathrm{~mm}^{2}\right)$. The correlation between CT and IVUS for the RI was similar in our study and theirs ( $\mathrm{r}=0.7$ vs 0.8 , respectively). Similarly, Moselewski et $a^{28}$ compared cross-sectional vessel area in 16-slice CT and IVUS. They observed a systematic overestimation of vessel area in CT with a mean difference of $0.9 \pm 4.0 \mathrm{~mm}^{2}$ as compared with IVUS. It is worth mentioning that the agreement between CT and IVUS measurements in our study is slightly better than the agreement reported in the Moselewski study. This can be probably explained by the different technology used in both studies. Temporal and spatial resolutions were higher in our study, and so was soft tissue contrast, with resulting effects on image quality.

Typically, a cut-off value of 1.05 is used for the RI to define plaques as 'positively remodelled' ${ }^{5}$ However, using ROC-curve analysis, we found that a cut-off $\mathrm{RI} \geq 1.1$ allowed better distinction of positively remodelled plaques in CT (area under the curve $=0.8,95 \%$ CI 0.7 to 1 ). Specificity was $78 \%$ compared with a specificity of $45 \%$ using the standard cut-off RI of 1.05 , yet sensitivity declined from 100\% to $83 \%$.

There are several limitations to be acknowledged. Only selected datasets of excellent or good image quality were included in this analysis, apart from the relative small sample size. Moreover, for determining the RI, we used the vessel diameter at the site of maximal narrowing and not at the site of maximal vessel area. There is no consensus as to which approach predicts better results. Furthermore, all vessel areas, whether at the lesion or reference site, were determined by manual tracing. Finally, it should be mentioned that the ultimate goal of atherosclerotic lesion analysis by CT is the identification of 'vulnerable plaques', and the quantification of positive remodelling is only a surrogate marker. The optimal validation of any approach would therefore be the comparison with outcome data. However, large patients groups and long follow-up would be required.

In summary, our study demonstrates that vessel area measurements in the presence of plaque tend to be overestimated in CT as compared with IVUS, and hence a RI with a slightly higher cut-off value of 1.1 should potentially be adopted to accurately classify plaques as positively remodelled in CT angiography.

Funding The study was supported by Bundesministerium für Bildung und Forschung (BMBF), Bonn, Germany (grant BMBF 01 EV 0708).

Competing interests SA received research support from Siemens and Bayer Schering Pharma.

\section{Patient consent Obtained.}

Ethics approval This study was conducted with the approval of the local ethics committee.

Provenance and peer review Not commissioned; externally peer reviewed.

\section{REFERENCES}

1. Pasterkamp G, Schoneveld AH, van der Wal AC, et al. Relation of arterial geometry to luminal narrowing and histologic markers for plaque vulnerability: the remodeling paradox. J Am Coll Cardiol 1998;32:655-62.

2. Varnava AM, Mills PG, Davies MJ. Relationship between coronary artery remodeling and plaque vulnerability. Circulation 2002;105:939-43.

3. Gyongyosi M, Yang P, Hassan A, et al. Intravascular ultrasound predictors of major adverse cardiac events in patients with unstable angina. Clin Cardiol 2000;23:507-15

4. Nakamura M, Nishikawa H, Mukai S, et al. Impact of coronary artery remodeling on clinical presentation of coronary artery disease: an intravascular ultrasound study. J Am Coll Cardiol 2001;37:63-9.

5. Schoenhagen P, Ziada KM, Kapadia SR, et al. Extent and direction of arterial remodeling in stable versus unstable coronary syndromes: an intravascular ultrasound study. Circulation 2000;101:598-603.

6. Takano M, Mizuno K, Okamatsu K, et al. Mechanical and structural characteristics of vulnerable plaques: analysis by coronary angioscopy and intravascular ultrasound. J Am Coll Cardiol 2001;38:99-104.

7. Motoyama S, Sarai M, Harigaya $\mathrm{H}$, et al. Computed tomographic angiography characteristics of atherosclerotic plaques subsequently resulting in acute coronary syndrome. J Am Coll Cardiol 2009;54:49-57.

8. Hermiller JB, Tenaglia AN, Kisslo $\mathrm{KB}$, et al. In vivo validation of compensatory enlargement of atherosclerotic coronary arteries. Am J Cardiol 1993;11:665-8.

9. Losordo DW, Rosenfield K, Kaufman J, et al. Focal compensatory enlargement of human arteries in response to progressive atherosclerosis. In vivo documentation using intravascular ultrasound. Circulation 1994;89:2570-7.

10. Mintz GS, Kent KM, Pichard AD, et al. Contribution of inadequate arterial remodeling to the development of focal coronary artery stenoses. An intravascular ultrasound study. Circulation 1997;95:1791-8.

11. Nishioka T, Luo H, Eigler NL, et al. Contribution of inadequate compensatory enlargement to development of human coronary artery stenosis: an in vivo intravascular ultrasound study. J Am Coll Cardiol 1996;27:1571-6.

12. von Birgelen C, Mintz GS, de Vrey EA, et al. Atherosclerotic coronary lesions with inadequate compensatory enlargement have smaller plaque and vessel volumes: observations with three dimensional intravascular ultrasound in vivo. Heart 1998;79:137-42.

13. von Birgelen C, Klinkhart W, Mintz GS, et al. Plaque distribution and vascular remodeling of ruptured and nonruptured coronary plaques in the same vessel: an intravascular ultrasound study in vivo. J Am Coll Cardiol 2001;37:1864-70.

14. Achenbach S. Cardiac CT: state of the art for the detection of coronary arterial stenosis. J Cardiovasc Comput Tomogr 2007;1:3-20.

15. Achenbach S, Daniel WG. Cardiac imaging in the patient with chest pain: coronary CT angiography. Heart 2010;96:1241-6.

16. Achenbach S, Moselewski F, Ropers D, et al. Detection of calcified and noncalcified coronary atherosclerotic plaque by contrast-enhanced, submillimeter multidetector spiral computed tomography: a segment-based comparison with intravascular ultrasound. Circulation 2004;109:14-17. 
17. Achenbach S, Raggi P. Imaging of coronary atherosclerosis by computed tomography. Eur Heart J 2010;31:1442-8.

18. Achenbach S, Ropers D, Kuettner A, et al. Contrast-enhanced coronary artery visualization by dual-source computed tomography-initial experience. Eur J Radiol 2006; 57:331-5

19. Ferencik M, Nieman K, Achenbach S. Noncalcified and calcified coronary plaque detection by contrast-enhanced multi-detector computed tomography: a study of interobserver agreement. J Am Coll Cardiol 2006;47:207-9.

20. Leber AW, Johnson T, Becker A, et al. Diagnostic accuracy of dual-source multislice CT-coronary angiography in patients with an intermediate pretest likelihood for coronary artery disease. Eur Heart J 2007;28:2354-60.

21. Ropers D, Pohle FK, Kuettner A, et al. Diagnostic accuracy of noninvasive coronary angiography in patients after bypass surgery using 64-slice spiral computed tomography with 330-ms gantry rotation. Circulation 2006:114:2334-41;quiz 2334.

22. Ropers D, Rixe J, Anders K, et al. Usefulness of multidetector row spiral computed tomography with 64- x 0.6-mm collimation and 330-ms rotation for the noninvasive detection of significant coronary artery stenoses. Am J Cardiol 2006;97:343-8.

23. Schmid M, Achenbach S, Ropers D, et al. Assessment of changes in non-calcified atherosclerotic plaque volume in the left main and left anterior descending coronary arteries over time by 64-slice computed tomography. Am J Cardiol

2008;101:579-84.

24. Schmid M, Pflederer T, Jang IK, et al. Relationship between degree of remodeling and CT attenuation of plaque in coronary atherosclerotic lesions: an in-vivo analysis by multi-detector computed tomography. Atherosclerosis 2008;197:457-64.

25. Sun Z, Jiang W. Diagnostic value of multislice computed tomography angiography in coronary artery disease: a meta-analysis. Eur J Radiol 2006;60:279-86.

26. Flohr TG, McCollough $\mathrm{CH}$, Bruder $\mathrm{H}$, et al. First performance evaluation of a dual-source CT (DSCT) system. Eur Radiol 2006;16:256-68.
27. van Velzen JE, Schuijf JD, de Graaf FR, et al. Plaque type and composition as evaluated non-invasively by MSCT angiography and invasively by VH IVUS in relation to the degree of stenosis. Heart 2009;95:1990-6.

28. Moselewski F, Ropers D, Pohle K, et al. Comparison of measurement of cross-sectional coronary atherosclerotic plaque and vessel areas by 16 -slice multidetector computed tomography versus intravascular ultrasound. Am J Cardiol 2004:94:1294-7.

29. Achenbach S, Ropers D, Hoffmann U, et al. Assessment of coronary remodeling in stenotic and nonstenotic coronary atherosclerotic lesions by multidetector spiral computed tomography. J Am Coll Cardiol 2004;43:842-7.

30. Hoffmann U, Moselewski F, Nieman K, et al. Noninvasive assessment of plaque morphology and composition in culprit and stable lesions in acute coronary syndrome and stable lesions in stable angina by multidetector computed tomography. J Am Coll Cardiol 2006;47:1655-62.

31. Motoyama S, Kondo T, Sarai M, et al. Multislice computed tomographic characteristics of coronary lesions in acute coronary syndromes. J Am Coll Cardiol 2007:50:319-26.

32. Pflederer T, Marwan M, Schepis T, et al. Characterization of culprit lesions in acute coronary syndromes using coronary dual-source CT angiography. Atherosclerosis 2010:211:437-44.

33. Kitagawa T, Yamamoto $\mathrm{H}$, Horiguchi J, et al. Characterization of noncalcified coronary plaques and identification of culprit lesions in patients with acute coronary syndrome by 64 -slice computed tomography. JACC Cardiovasc Imaging 2009;2:153-60.

34. Marwan M, Pflederer T, Schepis T, et al. Coronary vessel and luminal area measurement using dual-source computed tomography in comparison with intravascular ultrasound: effect of window settings on measurement accuracy. J Comput Assist Tomogr 2011;35:113-18.

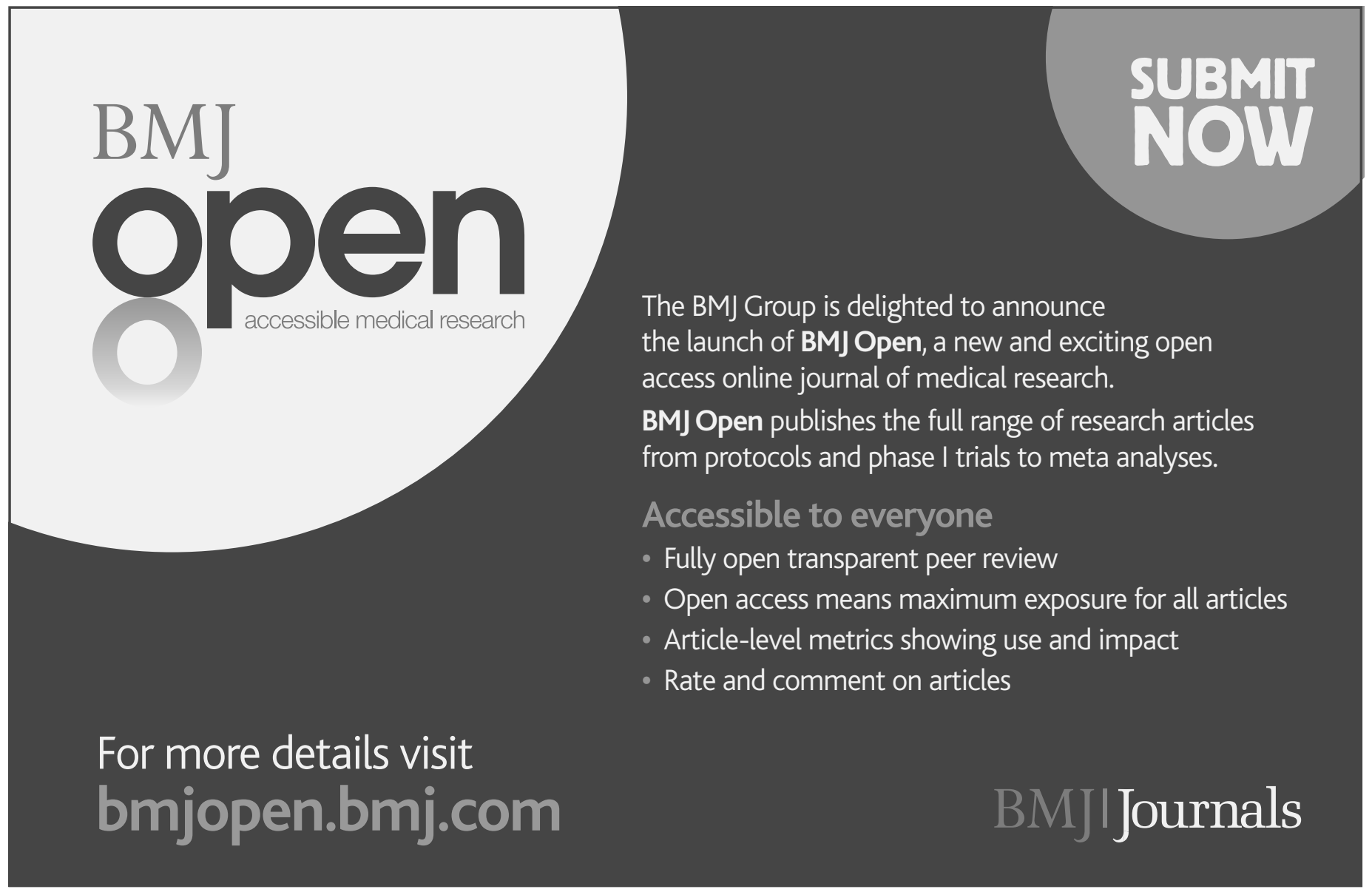




\section{Heart}

\section{Assessment of coronary artery remodelling by dual-source CT: a head-to-head comparison with intravascular ultrasound}

Sören Gauss, Stephan Achenbach, Tobias Pflederer, Annika Schuhbäck, Werner G Daniel and Mohamed Marwan

Heart 2011 97: 991-997 originally published online April 8, 2011 doi: 10.1136/hrt.2011.223024

Updated information and services can be found at:

http://heart.bmj.com/content/97/12/991

\section{These include:}

References This article cites 34 articles, 11 of which you can access for free at: http://heart.bmj.com/content/97/12/991\#BIBL

Email alerting service

Receive free email alerts when new articles cite this article. Sign up in the box at the top right corner of the online article.

Topic

Articles on similar topics can be found in the following collections Collections

\section{Notes}

To request permissions go to:

http://group.bmj.com/group/rights-licensing/permissions

To order reprints go to:

http://journals.bmj.com/cgi/reprintform

To subscribe to BMJ go to:

http://group.bmj.com/subscribe/ 